\title{
Assessment of postural deviation of selected women while mopping floor in squatting and standing posture
}

\author{
DEEPIKA SAVANT AND JAYSHREE RODGE
}

Received: 21.07.2015; Revised: 26.10.2015; Accepted: 04.11.2015

See end of the paper for authors' affiliations

\section{JAYSHREE RODGE}

Department of Family Resource Management, College of Home Science, Vasantrao Naik

Marathwada Krishi Vidyapeeth, PARBHANI (M.S.) INDIA

Email:dr.jayarodge@ rediffmail.com
ABSTRACT : The study entitled assessment of postural deviation of selected women while mopping floor in squatting and standing posture was conducted in Parbhani city of Marathwada region in Maharashtra state. Thirty women aged between 25-35 years involved in mopping activity was selected purposively to determine the postural deviation of selected women while mopping the floor in squatting and standing posture. It was found that the body of selected women was deviating more at cervical, lumbar and elbow joint while mopping in squatting posture. Statistically ' $t$ ' values showed a significant difference between angle of deviation at cervical, lumbar and elbow joint while mopping in squatting and standing posture. Statistically age of women in I group ( $25-30 \mathrm{yrs}$.) was highly significant with angle of postural deviation at cervical joint $\left(0.53^{* *}\right)$ while mopping in standing posture and significantly correlated with angle of postural deviation at elbow joint $\left(0.38^{*}\right)$. Second group of weight $(40-50 \mathrm{~kg})$ of women was negatively highly significant with angle of deviation at cervical joint $\left(-0.52^{* *}\right)$ while mopping in standing posture. Negatively highly significant correlation was found in I group of height $(135-145 \mathrm{~cm})$ of women and angle of postural deviation at cervical and lumbar joint $\left(-0.65^{* *}\right.$ and $\left.-0.55^{* *}\right)$ while mopping in squatting posture. For II group (146 $155 \mathrm{~cm})$ of height negative significant correlation was observed with cervical joint $(-0.42 *)$. Women in the III group $(156-165 \mathrm{~cm})$ of height showed highly significant correlation with cervical joint $(0.54 * *)$ and significant correlation with lumbar joint $(0.42 *)$ while mopping in squatting and standing posture. Women in the III group $(156-165 \mathrm{~cm})$ of height showed negatively highly significant correlation with angle of postural deviation at cervical joint ($\left.0.58^{* *}\right)$ while mopping in squatting posture and significant correlation with angle of postural deviation at lumbar joint $(0.42 *)$ while mopping in standing posture.

KEY WORDS: Postural deviation, Mopping floor, Squatting and standing posture

- HOW TO CITE THIS PAPER : Savant, Deepika and Rodge, Jayshree (2015). Assessment of postural deviation of selected women while mopping floor in squatting and standing posture. Asian J. Home Sci., 10 (2) : 360-363. 